\title{
Ionization potentials of nitriles - Photoelectron spectra of succinonitrile and glutaronitrile
}

\author{
Heidi M. Muchall and Nick H. Werstiuk
}

\begin{abstract}
The He(I) photoelectron spectra of succinonitrile (1) and glutaronitrile (2), both with extensive overlap of ionization bands in the low-energy region, are reported. To assign ionizations, we studied the conformational behaviour and resulting ionization energy dependence of 1 and 2 computationally with the B3LYP/6-31+G(d) model chemistry based on the fact that it reliably reproduces the ionization potentials of eleven mono- and di-nitriles, both saturated and unsaturated. The correlation of proton affinities with observed ionization potentials of $\mathbf{1}, \mathbf{2}$, and malononitrile establishes the orbital sequence of four $\mathrm{C} \equiv \mathrm{N} \pi$ orbitals followed by two nitrogen lone pair orbitals as the highest occupied molecular orbitals for all three compounds.
\end{abstract}

Key words: photoelectron spectrum, ionization potential, conformational dependence, nitrile, DFT.

Résumé : On a déterminé les spectres photoélectroniques He(I) du succinonitrile (1) et du glutaronitrile (2) qui présentent tous les deux un recouvrement important des bandes d'ionisation dans la région de basse énergie. Pour attribuer les ionisations, en se basant sur le fait qu'ils permettent de reproduire fidèlement les potentiels d'ionisation de onze mono- et dinitriles, tant saturés qu'insaturés, on a fait appel à des calculs théoriques au niveau B3LYP/6-31+G(d) pour effectuer une étude du comportement conformationnel des composés $\mathbf{1}$ et $\mathbf{2}$ et de la dépendance d'énergie d'ionisation qui en résulte. La corrélation des affinités protoniques avec les potentiels d'ionisation observés pour les composés $\mathbf{1}, \mathbf{2}$ et pour le malonitrile permettent d'établir que, pour les trois composés, la séquence orbitalaire des orbitales moléculaires hautes occupées sont les quatre orbitales $\pi \mathrm{du} C \equiv \mathrm{N}$, suivies par les orbitales de deux orbitales de paires célibataires de l'azote.

Mots clés : spectre photoélectronique, potentiel d'ionisation, dépendance conformationnelle, nitrile, théorie de la théorie de la fonctionnelle de densité.

[Traduit par la Rédaction]

\section{Introduction}

This study was prompted by a request for the ionization potentials (IPs) of succinonitrile (1), which were needed for a comparison with those from 1,2-dicyanocyclopropanes (1). As explained in the following, the interpretation of the photoelectron (PE) spectrum of 1, as well as that of glutaronitrile (2), turned into the comprehensive study reported here.

Two major problems have been reported with respect to the assignment of ionizations in nitriles. Firstly, Koopmans' theorem (2) seems to break down when model chemistries do not include electron correlation, which affected earlier analyses that made use of semiempirical or Hartree-Fock methods (3). Secondly, hole-mixing effects are reported to potentially further complicate the assignment of ionization events, even though the valence region seems to be little affected (4).

Received 11 July 2006. Accepted 14 September 2006.

Published on the NRC Research Press Web site at http://canjchem.nrc.ca on 27 October 2006.

H.M. Muchall. ${ }^{1}$ Centre for Research in Molecular Modeling and Department of Chemistry and Biochemistry, Concordia

University, Montreal, QC H4B 1R6, Canada.

N.H. Werstiuk. Department of Chemistry, McMaster

University, Hamilton, ON L8S 4M1, Canada.

${ }^{1}$ Corresponding author (e-mail: muchall@alcor.concordia.ca).
We expected to be able to make use of the methodology that we developed for the reliable calculation of ionization potentials of carbenes (5). The first ionization potential can be readily obtained as the difference in energy between a molecule and its radical cation at the geometry of the molecule (first vertical IP, $\mathrm{IP}_{\mathrm{v}, 1}$ ) or the optimized radical geometry of the cation (first adiabatic IP, $\mathrm{IP}_{\mathrm{a}, 1}$ ). Once the difference between the $\operatorname{IP}_{\mathrm{v}, 1}$ and the energy of the highest occupied molecular orbital (HOMO) is added onto the energies of all occupied molecular orbitals, "calculated IPs" are obtained that can be compared to those obtained from a PE spectrum. Because the correlation between the two sets of IPs is usually of high accuracy, with both slopes and correlation coefficients of a linear regression close to 1.0, the calculated values are of tremendous aid in the interpretation of a PE spectrum in the case of multiple overlapping bands. A goal of this study was, therefore, to evaluate whether the lowenergy ionizations of nitriles could be calculated reliably at the B3LYP/6-31+G(d) level of theory, as this model chemistry is highly efficient. Numerous PE spectra of nitriles are published and available for comparison with computational data and we chose nitriles $\mathbf{3 - 1 3}$ for our study because of their widely varying electronic structures.

In the following, we first evaluate the B3LYP/6-31+G(d) model chemistry for the determination of the low-energy ionization potentials of eleven nitriles, 3-13, whose PE spectra are available in the literature. Next, the PE spectra of $\mathbf{1}$ and $\mathbf{2}$ are reported for the first time (to the best of our 


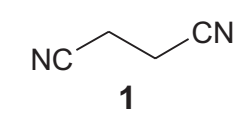<smiles>N#CCCCC#N</smiles>

$$
\begin{gathered}
\mathrm{H}-\mathrm{CN} \\
3
\end{gathered}
$$<smiles>CC#N</smiles><smiles>CCC#N</smiles>
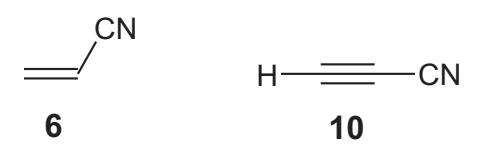

$$
\begin{gathered}
\mathrm{NC}-\mathrm{CN} \\
12
\end{gathered}
$$
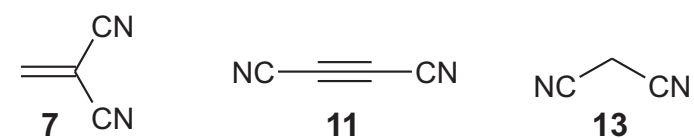

knowledge) and the assignment of their ionization bands is discussed with particular emphasis on the molecular flexibility and its implications. Finally, the matter of the relative position of $\pi$ and $n$ type ionizations in the dinitrile series, malono- (13), succino- (1), and glutaronitrile (2), is addressed.

\section{Experimental and computational details}

The He(I) photoelectron spectra were recorded on a locally built instrument (6). Linearity of the scale was ensured through calibrations with iodomethane (9.54 and $10.16 \mathrm{eV})$ (7) and nitrogen (15.60 eV) (7) performed prior to the experiments. To remove water from succinonitrile and glutaronitrile (both purchased from Sigma-Aldrich), samples were pumped in the PE spectrometer at elevated probe temperatures $\left(50-60{ }^{\circ} \mathrm{C}\right)$ and the process was followed by monitoring the PE spectra until the prominent ionization of water at $12.62 \mathrm{eV}$ (7) had disappeared and no further change between subsequent spectra was discernible. The final spectra (averages of 20 scans) were also run with a probe temperature of $50-60{ }^{\circ} \mathrm{C}$ with nitrogen as an internal calibrant as well as make-up gas (8) to increase the pressure and improve the signal-to-noise ratio.

All calculations were performed using the Gaussian 98 (9) or Gaussian 03 (10) suite of programs. Geometries of the (protonated) nitriles were fully optimized with the Becke3 (11) - Lee, Young, and Parr (12) hybrid density functional (B3LYP) with the 6-31+G(d) basis set; only indicated torsional angles were frozen in the torsional analyses. All minima were confirmed by harmonic vibrational frequency analyses and wave functions were checked for stability. Synthetic spectra were generated with a Fortran program PESPEC (13). The temperature was set to $300 \mathrm{~K}$ and ionization potentials are convoluted with a Gaussian line-shape with a full width at half height of 0.2. Molecular orbitals were plotted using GaussView 3.0 (14). All energies, total and otherwise, used in the calculation of ionization potentials and proton affinities are given in Table S1 in the Supplementary Information. $^{2}$

\section{Results and discussion}

\section{Ionization potentials of nitriles 3-13}

We decided to use the already published PE spectra of eleven mono- and di-nitriles, saturated and unsaturated, to evaluate our methodology for the calculation of ionization potentials (5). The prominent low-energy ionizations from $n$ and $\pi$ orbitals of $\mathbf{3 - 1 3}$ and ionizations from the onset of the $\sigma$-region reported in the literature are given in Table $1 . \mathrm{We}$ have calculated the first vertical ionization potentials $\left(\mathrm{IP}_{\mathrm{v}, 1}\right)$ of 3-13. These are also given in Table 1 together with the calculated orbital energies $\varepsilon$ and calculated IPs (obtained as explained in the introduction and in a footnote in Table 1).

As can be seen from Table 1, our calculated values for $\mathrm{IP}_{\mathrm{v}, 1}$ are within $0.5 \mathrm{eV}$ of the experimental values and in many cases the deviation is significantly less. Overall there is a very good agreement between experimental and calculated $\mathrm{IP}_{\mathrm{v}, 1}$ with a correlation coefficient $R^{2}$ of 0.9664 .

Individual plots of calculated vs. experimental $\mathrm{IP}_{\mathrm{v}}$ for mononitriles 3-5 (10 data points) and alkenes 6-9 (25 data points) suggest that two of the values reported in the literature should be revised. In Fig. $1 a$, the fifth ionization for propionitrile (5), reported at $14.25 \mathrm{eV}$ (7) and indicated with the symbol $\times$, is more likely to be at $13.8 \mathrm{eV}$ and a close reexamination of the PE spectrum seems to confirm this. This suggested shift, pointed out by the arrow in Fig. $1 a$, improves the correlation coefficient from 0.9781 to 0.9884 . In Fig. $1 b$, the third ionization for alkene 9, reported at $13.35 \mathrm{eV}$ (indicated with the symbol $\times$ ) $(15)$, should probably be at a smaller value. While the onset of the second band in the PE spectra of alkenes $\mathbf{6}-\mathbf{8}$ is sharp and starts from the baseline, there seems to be a shoulder on the low-energy side of the second band in the PE spectrum of 9, indicating a somewhat broader ionization band under the one given at $12.77 \mathrm{eV}$ (15). We suggest that the third ionization should then be located at $12.8 \mathrm{eV}$ instead, which improves the correlation coefficient from 0.9684 to 0.9818 .

In Fig. 2, we show the plot of calculated vs. experimental $\mathrm{IP}_{\mathrm{v}}$ with the previously mentioned revised values for nitriles 3-13. With a slope of close to one and an intercept near

\footnotetext{
${ }^{2}$ Supplementary data for this article are available on the journal Web site (http://canjchem.nrc.ca) or may be purchased from the Depository of Unpublished Data, Document Delivery, CISTI, National Research Council Canada, Ottawa, ON K1A 0R6, Canada. DUD 5086. For more information on obtaining material refer to http://cisti-icist.nrc-cnrc.gc.ca/irm/unpub_e.shtml.
} 
Table 1. Vertical ionization potentials and orbital energies $(\mathrm{eV})$ of nitriles 3-13.

\begin{tabular}{|c|c|c|c|c|c|}
\hline & Exp. $\mathrm{IP}_{\mathrm{v}}$ & $\mathrm{IP}_{\mathrm{v}, 1}{ }^{a}$ & $-\varepsilon$ & Calcd. $\mathrm{IP}^{b}$ & Refs. $^{c}$ \\
\hline \multirow[t]{3}{*}{3} & 13.60 & 13.67 & 10.09 & 13.67 & (7) \\
\hline & & & 10.09 & 13.67 & \\
\hline & 14.0 & & 10.70 & 14.28 & \\
\hline \multirow[t]{4}{*}{4} & 12.21 & 12.22 & 9.18 & 12.22 & (7) \\
\hline & & & 9.18 & 12.22 & \\
\hline & 13.14 & & 10.08 & 13.12 & \\
\hline & 16 & & 12.84 & 15.88 & \\
\hline \multirow[t]{5}{*}{5} & 11.90 & 11.79 & 9.05 & 11.79 & (7) \\
\hline & 12.06 & & 9.08 & 11.82 & \\
\hline & 12.83 & & 9.95 & 12.69 & \\
\hline & 13.56 & & 10.81 & 13.55 & \\
\hline & $14.25^{d}$ & & 11.09 & 13.83 & \\
\hline \multirow[t]{4}{*}{6} & 10.84 & 10.69 & 8.16 & 10.84 & (15) \\
\hline & 12.28 & & 9.45 & 12.28 & \\
\hline & 12.98 & & 10.22 & 12.98 & \\
\hline & 13.51 & & 10.60 & 13.51 & \\
\hline \multirow[t]{7}{*}{7} & 11.35 & 11.02 & 8.75 & 11.02 & (15) \\
\hline & 12.90 & & 10.05 & 12.32 & \\
\hline & 13.20 & & 10.31 & 12.58 & \\
\hline & 13.46 & & 10.39 & 12.66 & \\
\hline & 13.63 & & 10.85 & 13.12 & \\
\hline & 13.86 & & 11.05 & 13.32 & \\
\hline & 14.81 & & 12.09 & 14.36 & \\
\hline \multirow[t]{7}{*}{8} & 11.15 & 10.90 & 8.65 & 10.90 & (15) \\
\hline & 12.78 & & 10.09 & 12.34 & \\
\hline & 13.10 & & 10.25 & 12.50 & \\
\hline & 13.44 & & 10.72 & 12.97 & \\
\hline & & & 10.87 & 13.12 & \\
\hline & 13.67 & & 11.02 & 13.27 & \\
\hline & 14.41 & & 11.81 & 14.06 & \\
\hline \multirow[t]{7}{*}{9} & 11.15 & 10.88 & 8.61 & 10.88 & (15) \\
\hline & 12.77 & & 10.05 & 12.32 & \\
\hline & $13.35^{e}$ & & 10.06 & 12.33 & \\
\hline & 13.5 & & 10.57 & 12.84 & \\
\hline & 13.5 & & 10.79 & 13.06 & \\
\hline & 13.5 & & 10.88 & 13.15 & \\
\hline & 14.38 & & 11.75 & 14.02 & \\
\hline \multirow[t]{6}{*}{10} & 11.75 & 11.38 & 8.72 & 11.38 & (16) \\
\hline & & & 8.72 & 11.38 & \\
\hline & 13.54 & & 10.83 & 13.49 & \\
\hline & 14.18 & & 11.18 & 13.84 & \\
\hline & & & 11.18 & 13.84 & \\
\hline & 18.3 & & 15.52 & 18.18 & \\
\hline \multirow[t]{7}{*}{11} & 11.99 & 11.49 & 9.19 & 11.49 & (16) \\
\hline & & & 9.19 & 11.49 & \\
\hline & 13.91 & & 11.30 & 13.60 & \\
\hline & & & 11.30 & 13.60 & \\
\hline & 14.00 & & 11.51 & 13.81 & \\
\hline & 14.16 & & 11.55 & 13.85 & \\
\hline & 15.00 & & 12.41 & 14.71 & \\
\hline \multirow[t]{6}{*}{12} & 13.51 & 13.15 & 10.33 & 13.15 & (16) \\
\hline & & & 10.33 & 13.15 & \\
\hline & 14.49 & & 11.70 & 14.52 & \\
\hline & 14.86 & & 12.05 & 14.87 & \\
\hline & 15.6 & & 12.51 & 15.33 & \\
\hline & & & 12.51 & 15.33 & \\
\hline
\end{tabular}

Table 1 (concluded).

\begin{tabular}{lllrll}
\hline & Exp. $\mathrm{IP}_{\mathrm{v}}$ & $\mathrm{IP}_{\mathrm{v}, 1}{ }^{a}$ & \multicolumn{1}{c}{$-\varepsilon$} & Calcd. IP & ${\text { Refs }{ }^{c}}^{b}$ \\
\hline $\mathbf{1 3}$ & 12.72 & 12.28 & 9.81 & 12.28 & $(17)$ \\
13.14 & & 10.01 & 12.48 & \\
13.42 & & 10.26 & 12.73 & \\
13.59 & & 10.35 & 12.82 & \\
13.91 & & 10.88 & 13.35 & \\
14.06 & & 11.01 & 13.48 & \\
\hline
\end{tabular}

${ }^{a}$ Difference in electronic energy between a molecule and its radical cation at the geometry of the molecule.

${ }^{b}$ Obtained by a uniform shift of all orbital energies so that the HOMO energy matches the calculated $\mathrm{IP}_{\mathrm{v}, 1}$

${ }^{c}$ Experimental values.

${ }^{d}$ Should be at $13.8 \mathrm{eV}$, see text.

${ }^{e}$ Should be at $12.8 \mathrm{eV}$, see text.

Fig. 1. Correlation of calculated vs. experimental vertical ionization potentials for $(a)$ mononitriles 3-5 and $(b)$ alkenes 6-9.

Data points given with the symbol $\times$ were included in the correlations only after they were shifted as indicated by the arrows.
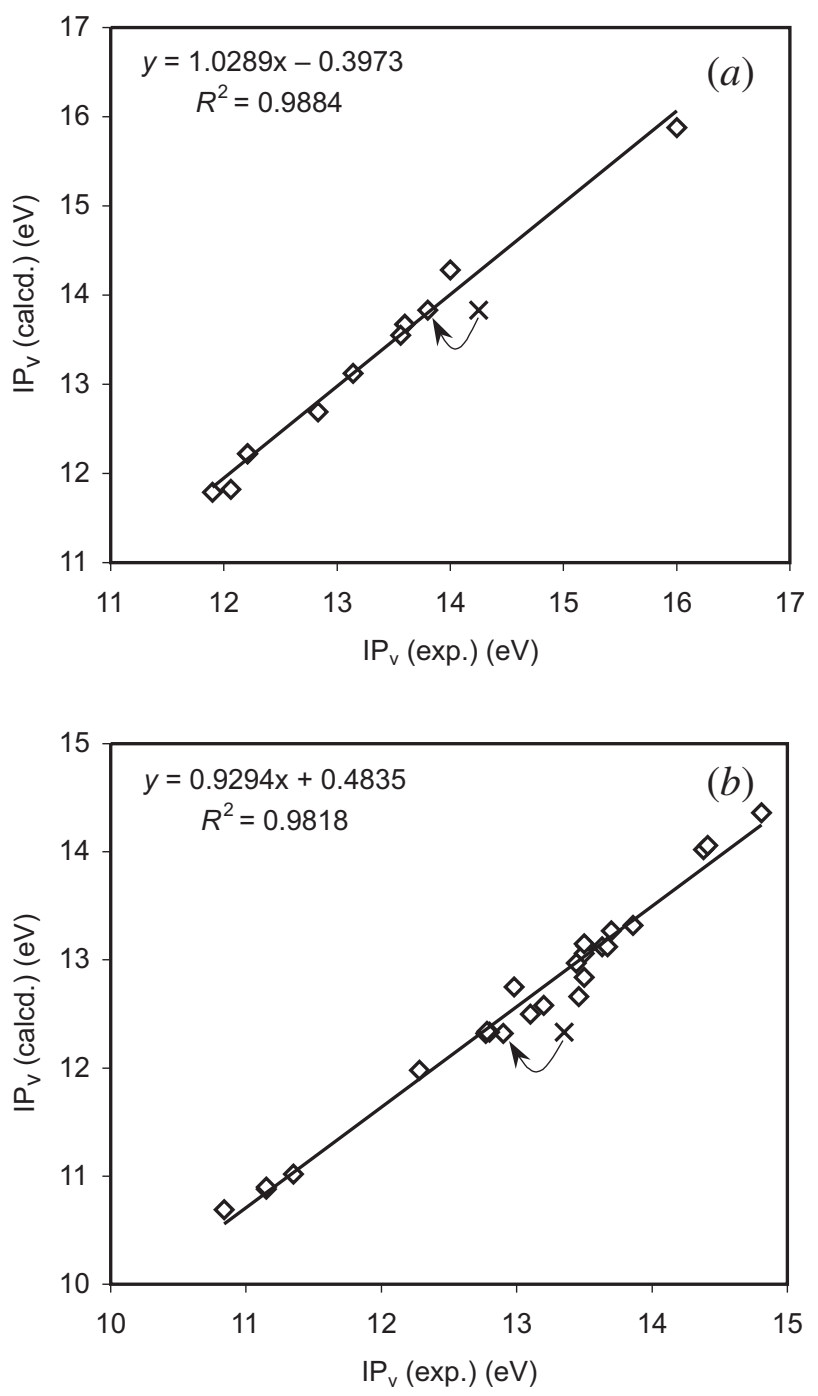
Fig. 2. Correlation of calculated and experimental vertical ionization potentials for nitriles $\mathbf{3}-\mathbf{1 3}$.

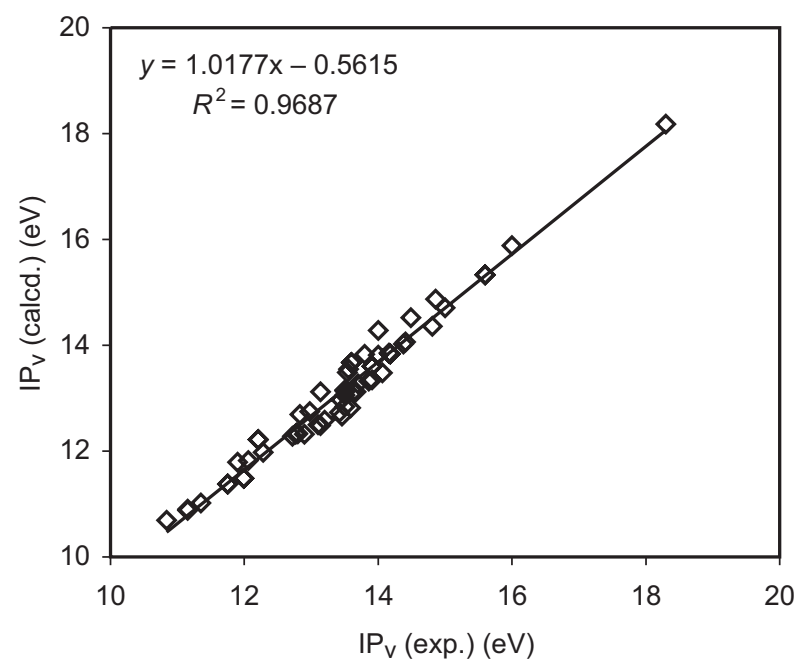

zero, this correlation demonstrates that our choice of model chemistry reliably reproduces the vertical ionization potentials of nitriles. Neither a larger basis set $(6-311+G(2 d, p))$ nor a switch to the Perdew-Burke-Ernzerhof (PBE0) (18) functional with either basis set produced a significant improvement over the results presented here (we performed calculations on selected nitriles only; the results for $\mathrm{IP}_{\mathrm{v}, 1}$ are given in Table $\mathrm{S} 2$ in the Supplementary Information). ${ }^{2}$

\section{Photoelectron spectra of 1 and 2}

The recorded photoelectron spectra of $\mathbf{1}$ and $\mathbf{2}$ are reported in Fig. 3. Owing to the relatively low vapour pressure of both 1 and 2 even at $50-60{ }^{\circ} \mathrm{C}$, nitrogen was used as a make-up gas during the acquisition of the spectra. The intense first ionization of nitrogen at $15.6 \mathrm{eV}$ is cut off arbitrarily in both spectra in Fig. 3. Both spectra exhibit extensive overlap of multiple ionization bands in the low-energy region (below $15 \mathrm{eV}$ for $\mathbf{1}$ and below $13.5 \mathrm{eV}$ for 2) and an interpretation of the spectra is only possible with the help of computational results. Accordingly, the assignment of the observed bands for $\mathbf{1}$ and $\mathbf{2}$ is performed in the following sections, taking the calculated ionization potentials and conformational flexibility of the molecules into account. The resulting interpretation in terms of low-energy ionization bands of $\mathbf{1}$ and $\mathbf{2}$ is given in Tables 2 and 3 and as vertical bars in Fig. 3.

\section{Interpretation of the PE spectra of 1 and 2}

While nitriles 3-13 do not possess conformational flexibility (apart from methyl group rotations that are irrelevant for our purposes), $\mathbf{1}$ and $\mathbf{2}$ can exist in several conformations and this can affect the appearance of the PE spectra if the conformers are close in energy and their orbital energies differ sufficiently $(19,20)$.

\section{Succinonitrile (1)}

The conformations of $\mathbf{1}$ have been studied computationally with ab initio methods as early as 1978 (21), with even earlier work on its torsional potential (22). For 1, a 1,2disubstituted ethane, two low-energy conformations can be identified, antiperiplanar 1ap and synclinal 1sc. While 1sc
Fig. 3. He(I) photoelectron spectra of (a) succinonitrile (1) and (b) glutaronitrile (2). The $\mathrm{N}_{2}$ (make-up gas) signal at $15.6 \mathrm{eV}$ is cut off. Assigned band positions are given by vertical bars.
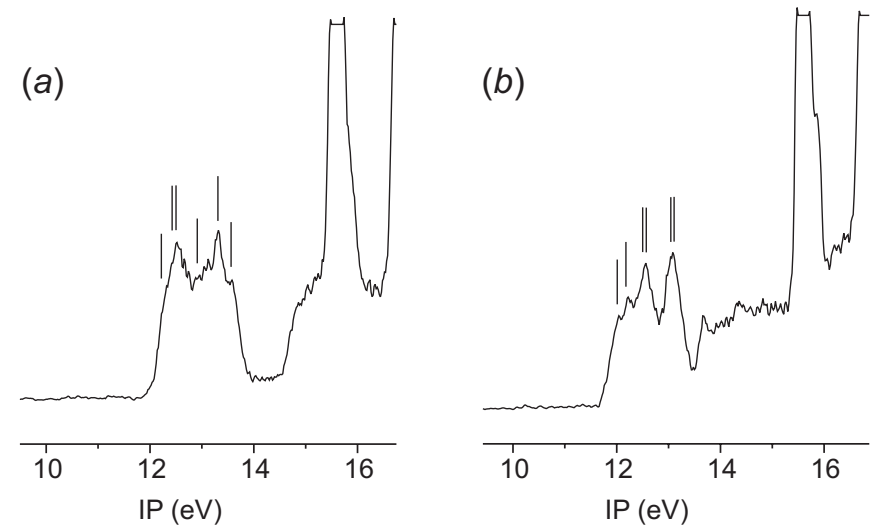

(C-C-C-C torsional angle is $69^{\circ}$ with B3LYP/6-31+G(d), $75^{\circ}$ from experiment (23)) is the form present in the solid below $-43.7{ }^{\circ} \mathrm{C}(24,25)$, in the gas phase we calculate a destabilization with respect to $\mathbf{1 a p}$ of $1.2 \mathrm{kcal} / \mathrm{mol}$ (B3LYP/6-31+G(d) based on either electronic energies or Gibbs free energies, $1 \mathrm{cal}=4.184 \mathrm{~J}$ ) in line with an early prediction (25). We find a similar destabilization of $1.1 \mathrm{kcal} / \mathrm{mol}$ with B3LYP/6-311+G(2d,p) and PBE0/6$311+\mathrm{G}(2 \mathrm{~d}, \mathrm{p})$ model chemistries, thus confirming that the smaller basis set is adequate for the description of $\mathbf{1}$. The energy difference leads to an equilibrium population of $78 \%$ 1ap and 22\% 1sc (combined amount for the two indistinguishable conformers +sc and -sc) at $300 \mathrm{~K}$, which is in excellent agreement with the $74 \%$ ap equilibrium at $170{ }^{\circ} \mathrm{C}$ found by electron diffraction in the gas phase (23).

Table 2 gives the calculated orbital energies and ionization potentials of 1ap and 1sc and it is obvious that even a small amount of 1sc in the equilibrium should influence the appearance of the PE spectrum of $\mathbf{1}$. To assess the IP dependence on the change in torsional angle that converts 1ap into 1sc, we have performed a relaxed potential energy scan twisting the $\mathrm{C}-\mathrm{C}-\mathrm{C}-\mathrm{C}$ torsional angle through $180^{\circ}$ and optimizing the rest of the molecule. The plot is shown in Fig. 4 for the first six calculated IPs (energies for HOMO to HOMO-5 shifted so that the HOMO energy for a torsional angle equals its first vertical ionization potential), which correspond to ionizations from the characteristic nitrile $\pi$ and $n$ orbitals. Orbital energies and calculated IPs for the different torsional angles are given in Table S3 in the Supplementary Information. ${ }^{2}$ Figure 4 demonstrates the predicted significant changes in IPs upon twisting of $\mathbf{1}$. Plots of the molecular orbitals of the $\mathrm{C}_{2 \mathrm{~h}}$-symmetrical 1ap are given in Fig. 5; the order of the orbitals is the same in 1sc. HOMO to HOMO-3

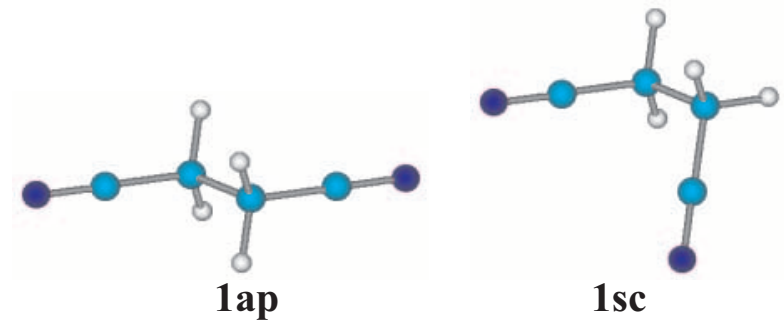


Table 2. Vertical ionization potentials and orbital energies (eV) of $\mathbf{1}$.

\begin{tabular}{|c|c|c|c|c|c|c|}
\hline \multirow[b]{2}{*}{ Exp. $\mathrm{IP}_{\mathrm{v}}$} & \multicolumn{3}{|l|}{ 1ap } & \multicolumn{3}{|l|}{$1 \mathrm{sc}$} \\
\hline & $\mathrm{IP}_{\mathrm{v}, 1}{ }^{a}$ & $-\varepsilon$ & Calcd. $\mathrm{IP}_{\mathrm{v}}{ }^{b}$ & $\mathrm{IP}_{\mathrm{v}, 1}{ }^{a}$ & $-\varepsilon$ & Calcd. $\mathrm{IP}_{\mathrm{v}}{ }^{b}$ \\
\hline 12.3 & 11.80 & 9.56 & 11.80 & 11.72 & 9.44 & 11.72 \\
\hline \multirow[t]{2}{*}{12.5} & & 9.67 & 11.91 & & 9.54 & 11.82 \\
\hline & & 9.72 & 11.96 & & 9.62 & 11.90 \\
\hline 13.0 & & 10.03 & 12.27 & & 9.90 & 12.18 \\
\hline 13.41 & & 10.53 & 12.77 & & 10.44 & 12.72 \\
\hline 13.50 & & 10.68 & 12.92 & & 10.47 & 12.75 \\
\hline
\end{tabular}

Note: The IPs reported here from re-recorded spectra differ slightly from the preliminary values given in (1). Also, see the included structures for the naming of the conformers.

${ }^{a}$ Difference in electronic energy between a molecule and its radical cation at the geometry of the molecule.

${ }^{b}$ Obtained by a uniform shift of all orbital energies so that the HOMO energy matches the calculated IP $\mathrm{P}_{\mathrm{v}, 1}$.

Table 3. Vertical ionization potentials and orbital energies $(\mathrm{eV})$ of $\mathbf{2}$.

\begin{tabular}{|c|c|c|c|c|c|c|c|c|c|}
\hline \multirow[b]{2}{*}{ Exp. $\mathrm{IP}_{\mathrm{v}}$} & \multicolumn{3}{|l|}{$2 g g$} & \multicolumn{3}{|l|}{$2 a g$} & \multicolumn{3}{|l|}{$2 \mathbf{a a}$} \\
\hline & $\mathrm{IP}_{\mathrm{v}, 1}^{a}$ & $-\varepsilon$ & Calcd. $\mathrm{IP}_{\mathrm{v}}{ }^{b}$ & $\mathrm{IP}_{\mathrm{v}, 1}^{a}$ & $-\varepsilon$ & Calcd. $\mathrm{IP}_{\mathrm{v}}{ }^{b}$ & $\mathrm{IP}_{\mathrm{v}, 1}^{a}$ & $-\varepsilon$ & Calcd. $\mathrm{IP}_{\mathrm{v}}^{\mathrm{b}}$ \\
\hline 12.04 & 11.45 & 9.33 & 11.45 & 11.36 & 9.25 & 11.36 & 11.39 & 9.31 & 11.39 \\
\hline \multirow{2}{*}{12.5} & & 9.50 & 11.62 & & 9.54 & 11.65 & & 9.50 & 11.58 \\
\hline & & 9.59 & 11.71 & & 9.71 & 11.82 & & 9.68 & 11.76 \\
\hline 13.1 & & 10.28 & 12.40 & & 10.26 & 12.37 & & 10.31 & 12.39 \\
\hline
\end{tabular}

Note: See the included structures for the naming of the conformers.

${ }^{a}$ Difference in electronic energy between a molecule and its radical cation at the geometry of the molecule.

${ }^{b}$ Obtained by a uniform shift of all orbital energies so that the HOMO energy matches the calculated $\mathrm{IP}_{\mathrm{v}, 1}$.

Fig. 4. Angular dependence of the first six ionization potentials of 1. Orbital energies for the torsional angle were uniformly shifted so that the HOMO energy equals the first calculated $\mathrm{IP}_{\mathrm{v}}$.

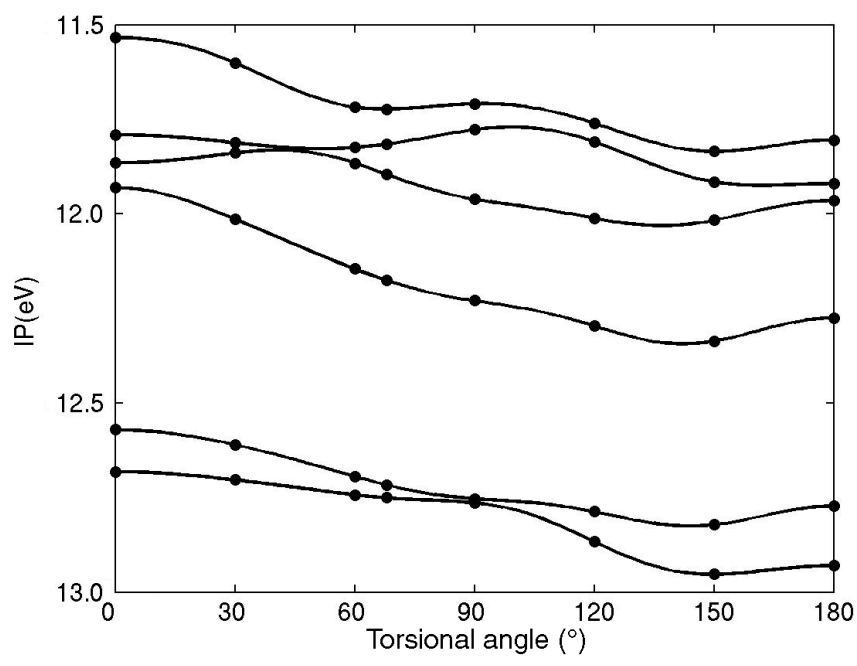

are $\pi$ type orbitals with additional coefficients on the linking $\mathrm{CH}_{2}$ groups; HOMO-4 and HOMO-5 are the two lone pair combinations, $\mathrm{n}_{\mathrm{N}}{ }^{+}$and $\mathrm{n}_{\mathrm{N}}{ }^{-}$. Ionizations arising from HOMO-1 and HOMO-2, the two out-of-plane orbitals $\pi_{\text {CNoop }}^{-}$and $\pi^{+}{ }_{\mathrm{CNoop}}$, as well as those from $\mathrm{n}_{\mathrm{N}}{ }^{+}$and $\mathrm{n}_{\mathrm{N}}{ }^{-}$show only a small splitting that could be attributed to through-bond interactions in the molecular orbitals. On the other hand, ionizations from HOMO and HOMO-3, the two in-plane orbitals $\pi_{\mathrm{CNip}}^{+}$ and $\pi^{-}$CNip, exhibit a somewhat constant splitting of about $0.4 \mathrm{eV}$ throughout the torsion.

The fitted potential for the torsion in $\mathbf{1}$ is shown in Fig. $6 a$ and we have simulated the PE spectrum of $\mathbf{1}$, given in Fig. $6 b$, based on this potential and the six IPs given in Fig. 4. A comparison between the experimental and the simulated spectrum shows good agreement in the low-energy part and it can be seen that six ionizations lie under the first two broad bands in the experimental spectrum of 1 (Fig. $3 a$ ). As well, the simulated spectrum suggests that the first ionization in Fig. $3 a$ should not be attributed to the maximum of the first band $(12.5 \mathrm{eV})$ but rather to a shoulder on its low-energy side at $12.3 \mathrm{eV}$. The first adiabatic IP $\left(\mathrm{IP}_{\mathrm{a}}\right)$ of $\mathbf{1}$ is at $11.9 \mathrm{eV}$ (Fig. 3a) and so the experimentally determined energy gap between first $\mathrm{IP}_{\mathrm{a}}$ and $\mathrm{IP}_{\mathrm{v}}$ of $0.4 \mathrm{eV}$ matches the calculated one (the $\mathrm{IP}_{\mathrm{a}}$ calculated for 1ap from $0-\mathrm{K}$ enthalpies is $11.52 \mathrm{eV})$.

The final band assignment for the ionizations of $\mathbf{1}$ is given in Table 2 and their position as vertical bars in Fig. $3 a$. As a final note, and keeping in mind that the discrimination in count rate between high- and low-energy electrons is different for the two spectrometers used, our spectrum of 1 resembles that of trans-1,2-dicyanocyclopropane (14) (1) with one fundamental exception. The major difference is caused by the stabilization of HOMO and HOMO-1 of 1 as compared to these orbitals in $\mathbf{1 4}$ by 0.8 and $0.5 \mathrm{eV}$, respectively, because in $14 \pi_{\mathrm{CN}}$ coefficients on the two nitrile groups are combined with two high-lying Walsh orbitals of the cyclopropyl group, $\omega_{S}$ and $\omega_{A}$. The stabilization of the two orbitals in $\mathbf{1}$ leads to a shift of the first two ionizations towards higher potentials and the subsequent extensive overlap 
Fig. 5. The six highest occupied molecular orbitals (HOMO to HOMO-5) of conformer 1ap, their characters and symmetries.
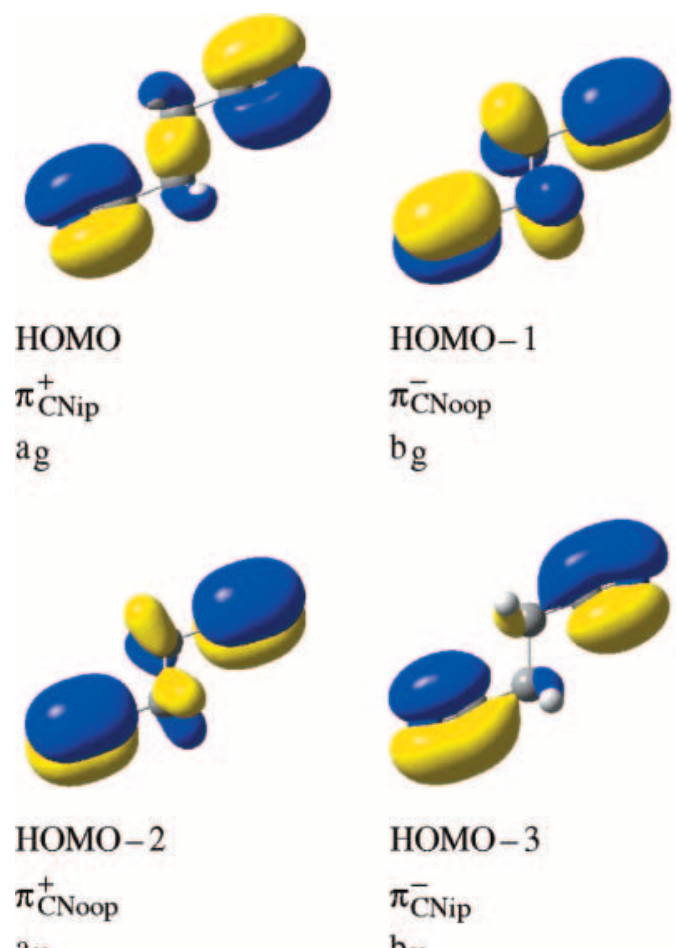

$\mathrm{a}_{\mathrm{u}}$

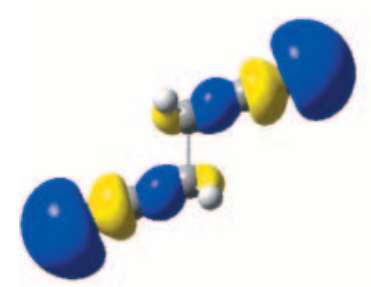

\section{HOMO-4}

$\mathrm{n}_{\mathrm{N}}^{+}$

ag
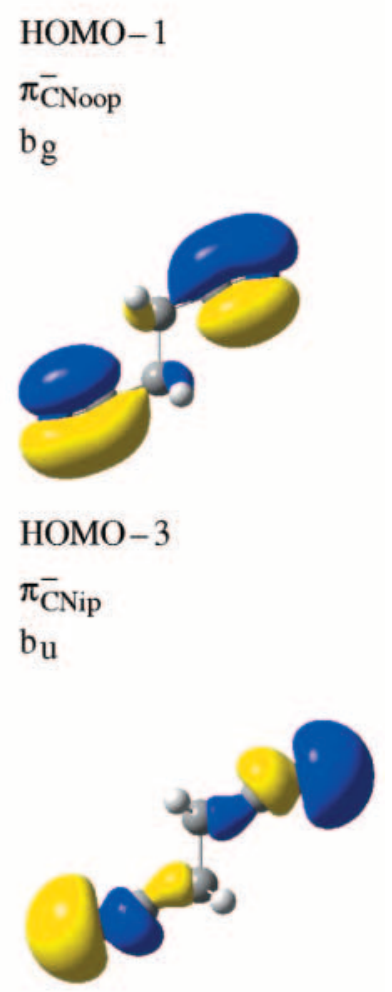

HOMO-5
$\mathrm{n}_{\overline{\mathrm{N}}}$
$\mathrm{b}_{\mathrm{u}}$

of bands in the spectrum of $\mathbf{1}$ that is not present in the spectrum of 14.

\section{Glutaronitrile (2)}

For 2, a 1,3-disubstituted propane, there are two torsional angles and conformations can be described as antiperiplanar (a) or synclinal/gauche (g) for either substituent (26) or using the trans $(\mathrm{T})$ and gauche $(\mathrm{G})$ notation in the older literature (27). The four possible conformers for $\mathbf{2}$ from B3LYP/631+G(d) electronic energies are 2gg (global minimum), $2 \mathbf{a g}(+0.4 \mathrm{kcal} / \mathrm{mol}), 2 \mathbf{a a}(+1.0 \mathrm{kcal} / \mathrm{mol})$, and $\mathbf{2} \mathbf{g g}^{-}$ $(+3.8 \mathrm{kcal} / \mathrm{mol})$. From these relative stabilities, with a statistical weight of two for a gg and four for an ag conformer, at $300 \mathrm{~K}$ the equilibrium is composed of $48 \% \mathbf{2 g g}, 47 \% \mathbf{2 a g}$, and $5 \%$ 2aa. The conformer $\mathbf{2} \mathbf{g g}^{-}$is too high in energy to contribute significantly. ${ }^{3}$ An approximately equimolar mix-

Fig. 6. (a) Torsional potential for twisting about the central $\mathrm{C}-\mathrm{C}$ bond in $\mathbf{1}$ and $(b)$ partial simulated PE spectrum of $\mathbf{1}$ based on the potential in $(a)$. Dashed lines in $(b)$ show the deconvoluted ionizations.
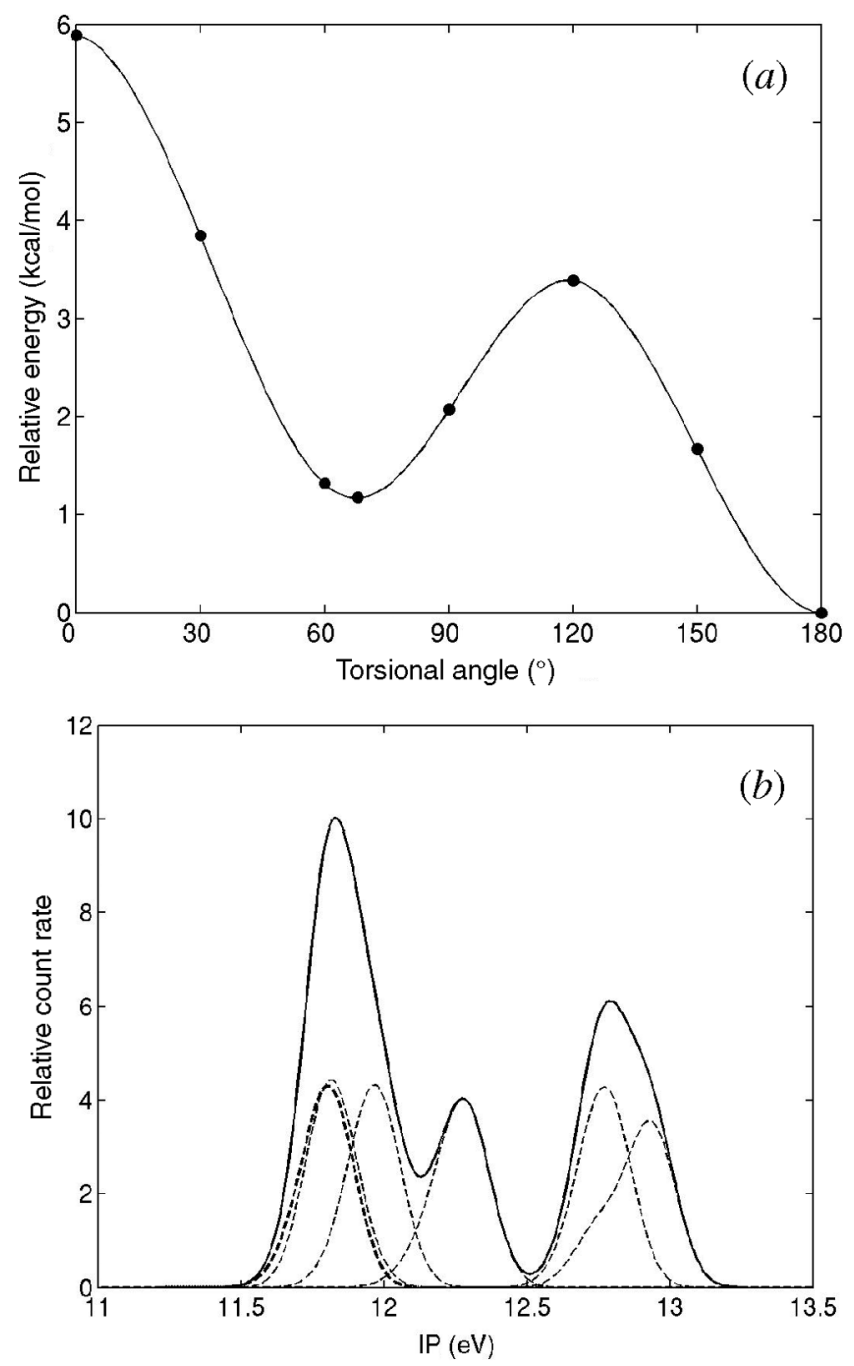

ture of $\mathbf{2 g g}$ and $\mathbf{2 a g}$ was also reported from an electron diffraction study at $448 \mathrm{~K}$ in the gas phase, but evidence for the presence of a small amount of 2aa was not found (28).

The MO sequence in the $\mathrm{C}_{2}$-symmetrical $\mathbf{2 g g}$ is $\pi^{+}$CNip (a symmetry), $\pi_{\text {CNoop }}$ (b symmetry), $\pi_{\text {CNip }}^{-}$(b), $\pi_{\text {CNoop }}^{+}$(a), $\mathrm{n}_{\mathrm{N}}{ }^{-}(\mathrm{b}), \mathrm{n}_{\mathrm{N}}{ }^{+}$(a). Pictures of the orbitals are similar to those given in Fig. 5. Some of these combinations are lost in $\mathbf{2 a g}$ and $\pi$ and $\mathrm{n}$ orbitals are localized on the individual $\mathrm{CN}$ groups, $\pi^{+}{ }_{\mathrm{CN}}, \pi_{\mathrm{CN}}, \pi_{\mathrm{CN}}, \pi_{\mathrm{CN}}^{-}, \mathrm{n}_{\mathrm{N}}, \mathrm{n}_{\mathrm{N}}$. Table 3 shows that orbital energies for the two conformers are very similar. To simulate the PE spectrum of $\mathbf{2}$, two torsional angles would have to be considered, a $\mathrm{CN}-\mathrm{C}-\mathrm{C}-\mathrm{C}$ that converts $\mathbf{2 g g}$ into $\mathbf{2 a g}$ and another for conversion of $\mathbf{2 g g}$ into $\mathbf{2 a a}$. We have checked the orbital energy dependence on the $\mathrm{CN}-\mathrm{C}-\mathrm{C}-\mathrm{C}$ torsional angle that relates the two major contributors, $\mathbf{2 g g}$ and 2ag. Not surprisingly, we find the dependence to be sim-

\footnotetext{
${ }^{3}$ As 2 gg and 2ag are approximately equal in energy, their equilibrium composition is about 1:1. This does not change when Gibbs free energies are considered even though $\mathbf{2 a g}$ is now more stable by $0.1 \mathrm{kcal} / \mathrm{mol}$.
} 


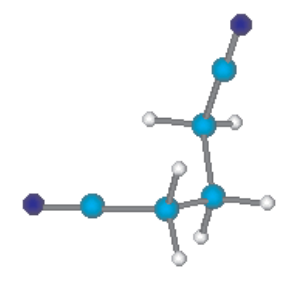

$2 g g$

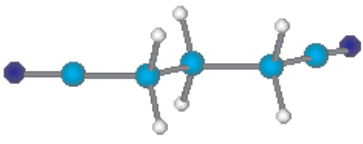

2aa

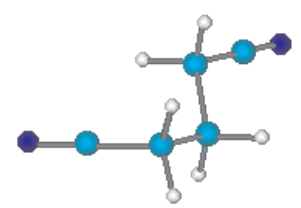

$2 a g$

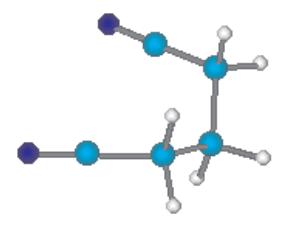

$2 \mathrm{gg}^{-}$ ilar to that in $\mathbf{1}$ but less pronounced (plot not shown). For these reasons we have not simulated the PE spectrum of 2.

With its onset $\left(\mathrm{IP}_{\mathrm{a}}\right)$ at $11.7 \mathrm{eV}$ and its maximum $\left(\mathrm{IP}_{\mathrm{v}}\right)$ at $12.0 \mathrm{eV}$ (Fig. 3b), the slope of the first ionization band is similar to that in the spectrum of $\mathbf{1}$. Unlike for $\mathbf{1}$, though, the adiabatic first IP for $\mathbf{2}$ is more difficult to assess computationally. A radical cation with a geometry close to that of $2 \mathrm{gg}$ does not exist at the B3LYP/6-31+G(d) level and removal of an electron from $\mathbf{2 g g}$ and geometry optimization leads to the transition state for a double hydride transfer instead. The calcd. $\mathrm{IP}_{\mathrm{a}}$ for $\mathbf{2} \mathbf{a g}$ (for which the optimized radical cation is a proper minimum) is $11.04 \mathrm{eV}$ and with calculated $\mathrm{IP}_{\mathrm{v}}$ values of 11.45 for $\mathbf{2 g g}$ and $11.36 \mathrm{eV}$ for $\mathbf{2} \mathbf{a g}$, the width-at-half-height of the first ionization band should be as is found experimentally. Overall, because of the similar IPs of $2 \mathrm{gg}$ and $2 \mathrm{ag}$ the presence of a second major conformer, be it $\mathbf{2 g g}$ or $\mathbf{2 a g}$, is not detectable. Because $\mathbf{2 a a}$ only contributes $5 \%$ to the equilibrium, its presence would only be noticeable if its first ionization potential were considerably lower than those of $\mathbf{2 g g}$ and $\mathbf{2 a g}$. Table 3 shows that this is not the case. The final band assignment for the ionizations of $\mathbf{2}$ is given in Table 3 and their position as vertical bars in Fig. $3 b$.

\section{Lone pair ionizations in dinitriles 1, 2, and 13}

The question of which are the lone pair ionizations in $\mathbf{1}$ and $\mathbf{2}$ is easier to answer than in malononitrile (13), for which several orbital sequences have been given $(4,17,29$, 30). For $\mathbf{1}$, the two $\mathrm{n}_{\mathrm{N}}$ ionizations are degenerate at a $\mathrm{C}-\mathrm{C}-$ $\mathrm{C}-\mathrm{C}$ torsional angle of $90^{\circ}$ (Fig. 4) and so the orbital energy dependence confirms the assignment given in Fig. 5. For $\mathbf{2}$, the two functional groups are far enough apart that they show hardly any interaction and consequently the energy gap between $\pi$ and $\mathrm{n}$ ionizations ( $0.7 \mathrm{eV}$ calculated for $\mathbf{2 g g}$ ) is similarly pronounced as those in the mononitriles $\mathbf{4}$ and $\mathbf{5}$ (0.9 eV calculated). In contrast, the reported order of orbitals and peak assignments for the first six ionization bands in $\mathbf{1 3}$ varies from $\pi, \pi, \mathrm{n}_{\mathrm{N}}{ }^{+}, \mathrm{n}_{\mathrm{N}}{ }^{-}, \pi, \pi$ (29) to $\pi, \pi, \pi, \mathrm{n}_{\mathrm{N}}{ }^{+}, \mathrm{n}_{\mathrm{N}}{ }^{-}, \pi$ (17) to $\pi, \pi, \pi, \pi, \mathrm{n}^{-}, \mathrm{n}^{+}(4)$; i.e., the potentials for the lone pair ionizations are progressively increased.
Staley et al. (30) have shown a linear correlation between the proton affinity (PA) of a nitrile and its $n_{N}$ ionization potential. While the data points for most mononitriles investigated (among these 3-6) fall close to the correlation line, the two IPs for the dinitrile $13\left(\mathrm{n}_{\mathrm{N}}{ }^{+}\right.$and $\left.\mathrm{n}_{\mathrm{N}}{ }^{-}\right)$are 6 and $10 \mathrm{kcal} / \mathrm{mol}$ too small when the original orbital sequence from Stafast and Bock (29) is used (30). This, among other reasons, led to a reassignment of the orbital order (17). We decided to use a similar correlation that would include $\mathbf{1}$ and 2 to confirm the orbital sequences we determined earlier. Calculating the proton affinity as the difference between the $0-\mathrm{K}$ enthalpies of the neutral and protonated molecules (for our purposes we can ignore temperature effects (31)), we find a good linear correlation $(y=1.419 x-82.83$, values in $\mathrm{kcal} / \mathrm{mol}, R^{2}=0.9945$, raw data are given in Table S4 in the Supplementary information $)^{2}$ between calculated and experimental PAs for the mononitriles 3-6. From this, our calculated PAs for 1ap $(176.2 \mathrm{kcal} / \mathrm{mol})$ and $\mathbf{2 g g}$ $(182.6 \mathrm{kcal} / \mathrm{mol})$ give estimated experimental PAs of 182.5 and $187.0 \mathrm{kcal} / \mathrm{mol}$, respectively. With these values, Fig. 7 allows the confirmation of the assigned lone pair ionizations in $\mathbf{1}$ and $\mathbf{2}$. It shows good linear correlation between the experimental $\mathrm{n}_{\mathrm{N}}$ ionization potential (Table 1) and the experimental PA of nitriles 3-6 (30). Superimposed are the first six ionization potentials of $\mathbf{1}$ and $\mathbf{2}$ at their estimated experimental PAs. Clearly, IPs around $13.5 \mathrm{eV}$ for $\mathbf{1}$ and around $13.2 \mathrm{eV}$ for $\mathbf{2}$ lie close to the regression line, confirming our assignment of these IPs to $\mathrm{n}_{\mathrm{N}}$ orbitals. In addition, Fig. 7 seems to support the orbital assignment of Cambi and von Niessen for 13, with four $\pi$ orbitals followed by two $n_{N}$ orbitals (4). At an experimental PA of $178.0 \mathrm{kcal} / \mathrm{mol}$, the fifth ionization, attributed to the higher-lying lone pair combination, lies close to the correlation line. The orbital sequence of $\mathbf{1 3}$ is thus in perfect agreement with that given above for both $\mathbf{1}$ and $\mathbf{2}$.

\section{Conclusions}

We have presented the $\mathrm{He}(\mathrm{I})$ photoelectron spectra of succinonitrile (1) and glutaronitrile (2). Even though the low-energy regions of both spectra exhibit extensive overlap of bands, it is possible to assign individual bands with the aid of calculated ionization potentials. Both $\mathbf{1}$ and $\mathbf{2}$ exhibit four $\pi$ orbitals followed by two nonbonding orbitals as the six highest occupied molecular orbitals. This orbital sequence was also established for the related malononitrile.

Finally, for nitriles of varying electronic structure (monoand di-nitriles, either saturated or unsaturated), the B3LYP/6-31+G(d) model chemistry allows vertical ionization potentials to be reproduced reliably. A violation of Koopmans' theorem for dinitriles is not found with this density functional theory method.

\section{Acknowledgements}

Calculations were performed at the Centre for Research in Molecular Modeling (CERMM), which was established with the financial support of the Concordia University Faculty of Arts and Science, the Ministère de l'Éducation du Québec (MEQ), and the Canada Foundation for Innovation (CFI). We also thank SHARCNET (Shared Hierarchical Academic 
Fig. 7. Linear regression of the measured $n_{N}$ ionization potential versus the experimental proton affinity (30) of nitriles 3-6 $(\times)$. Superimposed are the experimental IPs for the first six ionization events of $\mathbf{1}(\diamond), \mathbf{2}(\Delta)$, and $\mathbf{1 3}(\square)$ at their (estimated) PA values (see text).

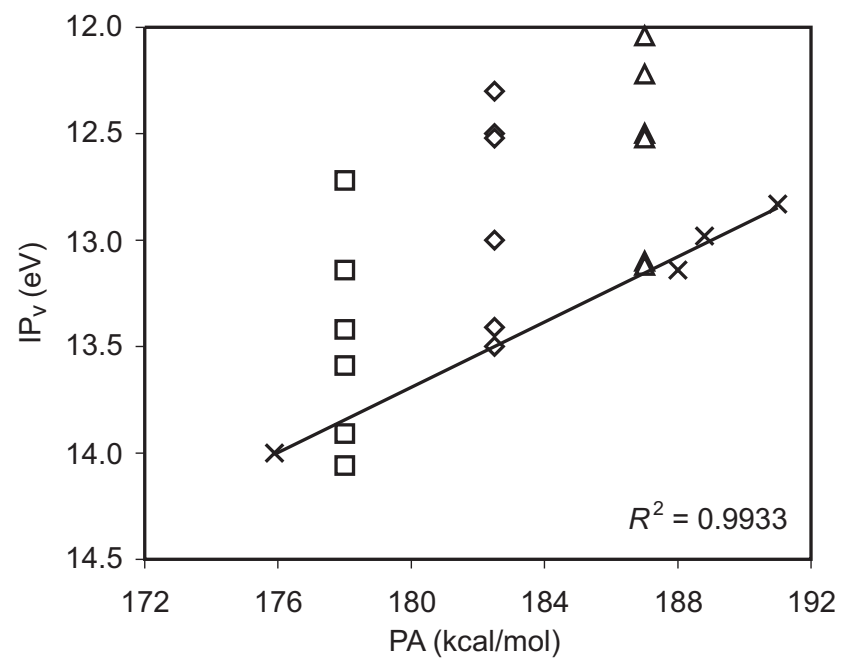

Research Computing Network of Ontario) for providing computing resources at McMaster University. This work was supported by research grants from the Natural Sciences and Engineering Research Council of Canada (NSERC).

\section{References}

1. P. Rademacher. Eur. J. Org. Chem. 7, 1572 (2004).

2. T. Koopmans. Physica, 1, 104 (1934).

3. P. Rosmus, H. Stafast, and H. Bock. Chem. Phys. Lett. 34, 275 (1975), and refs. cited therein.

4. R. Cambi and W. von Niessen. J. Electron. Spectrosc. Relat. Phenom. 42, 245 (1987).

5. H.M. Muchall, N.H. Werstiuk, and B. Choudhury. Can. J. Chem. 76, 221 (1998).

6. N.H. Werstiuk, D.N. Butler, and E. Shahid. Can. J. Chem. 65, 760 (1986).

7. K. Kimura, S. Katsumata, Y. Achiba, T. Yamazaki, and S. Iwata. In Handbook of HeI photoelectron spectra of fundamental organic molecules. Halsted Press, New York. 1981.

8. N.H. Werstiuk, H.M. Muchall, J. Ma, and M.T.H. Liu. Can. J. Chem. 76, 1162 (1998).

9. M.J. Frisch, G.W. Trucks, H.B. Schlegel, G.E. Scuseria, M.A. Robb, J.R. Cheeseman, V.G. Zakrzewski, J.J.A. Montgomery, R.E. Stratmann, J.C. Burant, S. Dapprich, J.M. Millam, A.D. Daniels, K.N. Kudin, M.C. Strain, O. Farkas, J. Tomasi, V. Barone, M. Cossi, R. Cammi, B. Mennucci, C. Pomelli, C. Adamo, S. Clifford, J. Ochterski, G.A. Peterson, P.Y. Ayala, Q. Cui, K. Morokuma, N. Rega, P. Salvador, J.J. Dannenberg, D.K. Malick, A.D. Rabuck, K. Raghavachari, J.B. Foresman, J. Cioslowski, J.V. Ortiz, A.G. Baboul, B.B. Stefanov, G. Liu, A. Liashenko, P. Piskorz, I. Komaromi, R. Gomperts, R.L. Martin, D.J. Fox, T. Keith, M.A. Al-Laham, C.Y. Peng, A. Nanayakkara, M. Challacombe, P.M.W. Gill, B. Johnson, W. Chen, M.W. Wong, J.L. Andres, C. Gonzalez, M. Head-
Gordon, E.S. Replogle, and J.A. Pople. Gaussian 98 [computer program]. Revision A.11.4. Gaussian, Inc., Pittsburgh, Pa. 2002.

10. M.J. Frisch, G.W. Trucks, H.B. Schlegel, G.E. Scuseria, M.A. Robb, J.R. Cheeseman, J.A. Montgomery, Jr., T. Vreven, K.N. Kudin, J.C. Burant, J.M. Millam, S.S. Iyengar, J. Tomasi, V. Barone, B. Mennucci, M. Cossi, G. Scalmani, N. Rega, G.A. Petersson, H. Nakatsuji, M. Hada, M. Ehara, K. Toyota, R. Fukuda, J. Hasegawa, M. Ishida, T. Nakajima, Y. Honda, O. Kitao, H. Nakai, M. Klene, X. Li, J.E. Knox, H.P. Hratchian, J.B. Cross, C. Adamo, J. Jaramillo, R. Gomperts, R.E. Stratmann, O. Yazyev, A.J. Austin, R. Cammi, C. Pomelli, J.W. Ochterski, P.Y. Ayala, K. Morokuma, G.A. Voth, P. Salvador, J.J. Dannenberg, V.G. Zakrzewski, S. Dapprich, A.D. Daniels, M.C. Strain, O. Farkas, D.K. Malick, A.D. Rabuck, K. Raghavachari, J.B. Foresman, J.V. Ortiz, Q. Cui, A.G. Baboul, S. Clifford, J. Cioslowski, B.B. Stefanov, G. Liu, A. Liashenko, P. Piskorz, I. Komaromi, R.L. Martin, D.J. Fox, T. Keith, M.A. Al-Laham, C.Y. Peng, A. Nanayakkara, M. Challacombe, P.M.W. Gill, B. Johnson, W. Chen, M.W. Wong, C. Gonzalez, and J.A. Pople. Gaussian 03 [computer program]. Revision B.02. Gaussian, Inc., Pittsburgh, Pa. 2003.

11. A.D. Becke. J. Chem. Phys. 98, 5648 (1993).

12. C. Lee, W. Young, and R.G. Parr. Phys. Rev. B, 37, 785 (1988).

13. N.H. Werstiuk, G. Timmins, J. Ma, and T.A. Wildman. Can. J. Chem. 70, 1971 (1992).

14. R. Dennington, II, T. Keith, J. Millam, K. Eppinnett, W.L. Hovell, and R. Gilliland. GaussView [computer program]. Version 3.09. Semichem, Inc., Shawnee Mission, Kans. 2003.

15. H. Stafast and H. Bock. Tetrahedron, 32, 855 (1976).

16. L. Åsbrink, W. von Niessen, and G. Bieri. J. Electron Spectrosc. Relat. Phenom. 21, 93 (1980).

17. C.B. Macdonald, D.S. Waddell, and N.P.C. Westwood. J. Mol. Struct. 162, 341 (1987).

18. J.P. Perdew, K. Burke, and M. Ernzerhof. Phys. Rev. Lett. 77, 3865 (1996); J.P. Perdew, K. Burke, and M. Ernzerhof. Phys. Rev. Lett. 78, 1396 (1997); J.P. Perdew, M. Ernzerhof, and K. Burke. J. Chem. Phys. 105, 9982 (1996).

19. E. Honegger and E. Heilbronner. Chem. Phys. Lett. 81, 615 (1981).

20. H.M. Muchall, N.H. Werstiuk, J. Ma, T.T. Tidwell, and K. Sung. Can. J. Chem. 75, 1851 (1997).

21. K. Kveseth. Acta Chem. Scand. Ser. A, 32, 51 (1978).

22. L. Radom and P.J. Styles. J. Chem. Soc. Chem. Commun. 190 (1974).

23. L. Fernholt and K. Kveseth. Acta Chem. Scand. Ser. A, 33, 335 (1979).

24. T. Fujiyama, K. Tokumaru, and T. Shimanouchi. Spectrochim. Acta, 20, 415 (1964).

25. W.E. Fitzgerald and G.J. Janz. J. Mol. Spectrosc. 1, 49 (1957).

26. E.L. Eliel and S.H. Wilen. In Stereochemistry of organic compounds. Wiley Interscience, New York. 1994. Chap. 10.

27. I. Matsubara. J. Chem. Phys. 35, 373 (1961).

28. P.J. Stavnebrekk. J. Mol. Struct. 213, 271 (1989).

29. H. Stafast and H. Bock. Z. Naturforsch. B, 28, 746 (1973).

30. R.H. Staley, J.E. Kleckner, and J.L. Beauchamp. J. Am. Chem. Soc. 98, 2081 (1976), and refs. cited therein.

31. E.I. von Nagy-Felsobuki and K. Kimura. J. Phys. Chem. 94, 8041 (1990). 